\title{
Comparison between retrograde intrarenal surgery and percutaneous nephrolithotripsy in the management of renal stones: A meta-analysis
}

\author{
MING ZHU ${ }^{1}$, XIAOYI WANG ${ }^{1}$, ZHANQIN SHI $^{1}$, MIN DING $^{1}$, DEYONG FAN $^{2}$, XIANG WANG $^{1}$ and RUI JIANG $^{2}$ \\ ${ }^{1}$ Nephrology Department, First Affiliated Hospital, Huzhou Teachers College, The First People's Hospital of Huzhou, \\ Huzhou, Zhejiang 313000; ${ }^{2}$ Nephrology Department, Huzhou Central Hospital, Huzhou, Zhejiang 313003, P.R. China
}

Received May 27, 2016; Accepted April 7, 2017

DOI: $10.3892 /$ etm. 2019.7710

\begin{abstract}
Percutaneous nephrolithotripsy (PCNL) is recommended as the first-line treatment for the management of kidney stones that are $\geq 2 \mathrm{~cm}$ in diameter. Retrograde intrarenal surgery (RIRS) has become increasingly preferred due to its high level of safety and repeatability, particularly in small stones. However, whether PCNL has superior efficacy and lower complication rates when compared with RIRS remains controversial. Therefore, the present meta-analysis was conducted to compare the clinical outcomes of patients treated with PCNL and RIRS as therapy for renal stones. Clinical trials published in PubMed, Web of Science, Excerpta Medica dataBASE (EMBASE), and the Chinese Biomedical Database (CBM) were systematically reviewed to evaluate the efficacy and safety profiles of patients with renal stones who were treated with PCNL or RIRS. Main outcomes measures included stone-free rate, operative time, hospital stay, and complication rate. Results were expressed as risk ratio (RR), or weighted mean difference (WMD) with $95 \%$ confidence intervals (CIs). Pooled estimates were calculated using a fixed-effects or random-effects model according to the heterogeneity among the studies. In total, 17 studies [4 randomized controlled trials (RCTs) and 13 cohort studies] involving 1,717 patients met the inclusion criteria, and were included in this meta-analysis. Pooled results showed that PCNL exhibited a significantly higher stone-free rate $(\mathrm{R} R=0.90,95 \% \mathrm{CI}$ : 0.86 to 0.95 ; $\mathrm{P}<0.001)$ but was associated with a longer hospital stay, when compared with RIRS (WMD $=-2.72,95 \% \mathrm{CI}:-3.9$ to -1.54; $\mathrm{P}<0.001$ ). Operative time (WMD=7.86, 95\% CI: -0.89 to $16.61 ; \mathrm{P}=0.078)$ and complication rate $(\mathrm{RR}=0.71,95 \% \mathrm{CI}$ : 0.48 to $1.05 ; \mathrm{P}=0.083$ ) did not significantly differ between the
\end{abstract}

Correspondence to: Dr Rui Jiang, Nephrology Department, Huzhou Central Hospital, 198 Hong Qi Road, Huzhou, Zhejiang 313003, P.R. China

E-mail: ruijiangrj@126.com

Key words: percutaneous nephrolithotripsy, retrograde intrarenal surgery, renal stones, meta-analysis groups. Subgroup analysis revealed that PCNL had a shorter operation time than RIRS in patients with stone sizes $\geq 2 \mathrm{~cm}$ (WMD=12.88, 95\% CI: 4.77 to 20.99; $\mathrm{P}=0.002$ ), and PCNL had a similar stone-free rate as RIRS when the estimates were pooled from $\mathrm{RCTs}(\mathrm{RR}=0.88,95 \% \mathrm{CI}$ : 0.76 to $1.01 ; \mathrm{P}=0.078)$. Compared with PCNL, RIRS had a significantly lower stone-free rate, shorter hospital stay, but a similar operation time and complication rate. Therefore, we propose that RIRS may be an alternative therapy to PCNL, with acceptable efficacy and complication rates for renal stones. Further large-scale, well-conducted RCTs are required to verify our findings.

\section{Introduction}

Nephrolithiasis is a very common illness that affects $5 \%$ of the population in the United States (1). It may result in chronic renal disease, and ultimately end-stage kidney disease, if left untreated. In the past two decades, owing to the technological improvements and miniaturization of instruments, the treatment for kidney stone disease has changed dramatically (1).

Percutaneous nephrolithotripsy (PCNL) is recommended by guidelines on Urolithiasis as the first-line treatment for the management of kidney stones $\geq 20 \mathrm{~mm}$ (2). Although it has been reported that PCNL has high success rates (>95\%), there are still several significant complications associated with this procedure, including urinary extravasation, bleeding necessitating transfusion, postoperative fever, and septicaemia $(3,4)$.

Retrograde intrarenal surgery (RIRS) is a procedure that has been considered in the management of smaller stones, or subsequently, after RIRS with a semirigid ureteroscope to disintegrate debris in the low calyx (5). Since the procedure is involved with long leaning curves and high rates of fiber breakage, the complication rate and costs of the procedure are high. According to retrospective studies, RIRS appears to be less invasive and safer but also less effective in the treatment of kidney stones, when compared with PCNL. Furthermore, due to the technological improvements in the design of modern ureteroscopes, RIRS has also been frequently considered in the treatment of larger renal stones as an alternative to PCNL $(5,6)$. However, whether RIRS is superior to PCNL in the management of renal stones remains controversial. Therefore, the 
present meta-analysis was conducted to compare the efficacy and safety of PCNL and RIRS in the treatment of renal stones.

\section{Materials and methods}

Search strategy. The following electronic databases were searched for relevant articles without language restrictions: PubMed (ncbi.nlm.nih.gov/pubmed), Web of Science (webofknowledge.com), Excerpta Medica dataBASE (EMBASE; embase.com), and the Chinese Biomedical Database (CBM; http://www.sinomed.ac.cn/).

The following search items were used: ['Kidney calculi' (MeSH Terms)] OR ['kidney' (All Fields) AND 'calculi' (All Fields)] OR ['kidney calculi' (All Fields)] OR ['renal' (All Fields) AND 'calculus' (All Fields)] OR ['renal calculus' (All Fields) AND retrograde (All Fields) AND intrarenal (All Fields) AND ‘surgery' (Subheading)] OR ['surgery' (All Fields)] OR ['surgical procedures, operative' (MeSH Terms)] OR ['surgical' (All Fields) AND 'procedures' (All Fields) AND 'operative' (All Fields)] OR ['operative surgical procedures' (All Fields)] OR ['surgery' (All Fields)] OR ['general surgery' (MeSH Terms)] OR ['general' (All Fields) AND 'surgery' (All Fields)] OR ['general surgery' (All Fields) AND 'nephrostomy, percutaneous' (MeSH Terms)] OR ['nephrostomy' (All Fields) AND 'percutaneous' (All Fields)] OR ['percutaneous nephrostomy' (All Fields)] OR ['percutaneous' (All Fields) AND 'nephrolithotomy' (All Fields)] OR ['percutaneous nephrolithotomy' (All Fields)].

Selection criteria. Inclusion criteria that an eligible study had to meet were as follows: i) Study design: RCT or cohort study; ii) study population: Patients with a solitary renal stone; iii) study intervention: Patients were treated either by RIRS or PCNL; iv) and outcome measures: Stone-free rate, hospital stay, operation time, and complication rate. Exclusion criteria included: i) Reviews, letters, case report, or abstracts; ii) patients had anatomic anomalies of kidney; iii) patients were not treated with RIRS or PCNL; and iv) did not provide one of these interest outcomes.

Data extraction. Two independent investigators extracted the following information for each study: First author's name, year of publication, number of patients (RIRS group and PCNL group), mean operation time, mean hospital stay, stone-free rate and complication rate. A standardized Excel file was used to extract the data. When the same trial appeared in different publications, we chose the article with the most information or the latest data. Disagreements between the investigators were resolved through discussion and consensus.

Methodological assessments. We applied the Jadad scale (7) to assess the methodological quality of RCTs. The scale consists of three items, including randomization (0-2 points), blinding (0-2 points), and dropouts and withdrawals ( $0-1$ point). The total score is 5 points. Studies with a score $\geq 3$ points are considered to be of high quality (8). For cohort studies, we used the modified Newcastle-Ottawa Scale (NOS) (9), which assesses studies using information on patients selection, comparability of RIRS and PCNL group, and an assessment of the outcomes of interest. The scale ranged from 0 to 9 stars, and studies with a quality score of $\geq 6$ were considered to be of high quality (9).

Statistical analysis. All analyses were conducted using STATA version 12.0 (Stata Corp., College Station, TX, USA). Heterogeneity among the included studies was assessed with Cochran's Q test (10) and $I^{2}$ statistic (11), in which $I^{2}>50 \%$, or $\mathrm{P}<0.10$ was considered as statistically significant heterogeneity (11). When significant heterogeneity was identified, a random-effect model (DerSimonian-Laird method) (12) was used to calculate parameters; otherwise, a fixed-effect model (Mantel-Haenszelmethod) (10) was used to pool data. For dichotomous variables, including stone-free rate and incidence of complications, the number of cases and total number of patients were extracted from the included studies. Thereafter, they were expressed as a risk ratio (RR) with $95 \%$ confidence intervals (CIs). For continuous variables, including duration of hospital stay and duration of operative time, the mean value and standard deviation (SD) were extracted from the included studies. Thereafter, the weighted mean difference (WMD) with 95\% CIs was calculated. Subgroup analysis was also performed based on the stone size or study design to explore potential sources of heterogeneity. Publication bias was evaluated by Begg's (13) and Egger's (14) tests. A P<0.05 was considered to indicate a statistically significant difference, except when otherwise specified.

\section{Results}

Identification of eligible studies. A total of 784 studies were initially retrieved in the literature search, including 169 in PubMed, 78 in Web of Science, 488 in EMBASE, and 49 in CBM. After checking for duplicates, 443 publications were eligible for inclusion in the meta-analysis. Of these, 367 studies were excluded after the title/abstract review, and 59 studies were excluded after the full-text review. Finally, 4 RCTs and 13 cohort studies were included in this meta-analysis (15-31). A flow chart of the search strategy is shown in Fig. 1.

Study characteristics. Table I presents the main characteristics of included studies. Baseline demographics in each study were comparable between the PCNL and RIRS groups, in terms of age, stone size, number and the locations of stones. All the studies were published in peer-reviewed journals between 2008 and 2015. The sample size of these studies ranged from 27 to 280 . Of the 17 studies, 4 were RCTs $(16,20,21,25)$, and the remaining 13 were cohort studies (15,17-19,22-24,26-31). Although the stone sizes among these studies were variable, most studies provided the outcome data in two groups: $<2 \mathrm{~cm}$ group and 2-3 cm group.

Quality assessment. NOS scores for 13 cohort studies ranged from 7 to 8, and Jadad scores for 4 RCTs ranged from 3 to 4 . This indicated that all the included studies were of high quality.

Stone-free rate. All studies reported the stone-free rate (15-31). Pooling of all the studies using a random effects model showed that the stone-free rate was significant lower in the RIRS group than that in the PCNL group (RR=0.90, 95\% CI: 0.86 to 0.95; $\mathrm{P}<0.001$; Fig. 2). There was statistical heterogeneity among 
Table I. Baseline characteristics of patients in the trials included in the present meta-analysis.

\begin{tabular}{|c|c|c|c|c|c|c|c|}
\hline Study & $\begin{array}{l}\text { Study } \\
\text { design }\end{array}$ & Surgery & $\begin{array}{c}\text { Case } \\
\text { no. }\end{array}$ & $\begin{array}{l}\text { Age, } \\
\text { years }\end{array}$ & $\begin{array}{c}\text { Stone size, } \\
\mathrm{mm}\end{array}$ & $\begin{array}{l}\text { NOS } \\
\text { score }\end{array}$ & (Refs.) \\
\hline Akman et al & Cohort & $\begin{array}{l}\text { PCNL } \\
\text { RIRS }\end{array}$ & $\begin{array}{l}34 \\
34\end{array}$ & $\begin{array}{l}44.8 \pm 17.1 \\
44.5 \pm 16.5\end{array}$ & $\begin{array}{l}\text { NR } \\
\text { NR }\end{array}$ & 7 & (15) \\
\hline Bryniarski et al & $\mathrm{RCT}$ & $\begin{array}{l}\text { PCNL } \\
\text { RIRS }\end{array}$ & $\begin{array}{l}32 \\
32\end{array}$ & $\begin{array}{l}51.8 \pm 11.8 \\
53.4 \pm 12.4\end{array}$ & $\begin{array}{l}>20 \\
>20\end{array}$ & 4 (Jadad score) & (16) \\
\hline Pan et al & Cohort & $\begin{array}{l}\text { PCNL } \\
\text { RIRS }\end{array}$ & $\begin{array}{l}59 \\
56\end{array}$ & $\begin{array}{l}49.37 \pm 14.2 \\
49.32 \pm 13.7\end{array}$ & $\begin{array}{l}22.37 \pm 2.7 \\
22.28 \pm 2.6\end{array}$ & 8 & (17) \\
\hline Hyams and Shah & Cohort & $\begin{array}{l}\text { PCNL } \\
\text { RIRS }\end{array}$ & $\begin{array}{l}20 \\
19\end{array}$ & $\begin{array}{l}48 \\
56\end{array}$ & $\begin{array}{l}20-30 \\
20-30\end{array}$ & 7 & (18) \\
\hline Li et al & Cohort & $\begin{array}{l}\text { PCNL } \\
\text { RIRS }\end{array}$ & $\begin{array}{l}30 \\
24\end{array}$ & $\begin{array}{l}26.4 \pm 5.5 \\
26.4 \pm 5.5\end{array}$ & $\begin{array}{l}\text { NR } \\
\text { NR }\end{array}$ & 6 & (19) \\
\hline Guo et al & $\mathrm{RCT}$ & $\begin{array}{l}\text { PCNL } \\
\text { RIRS }\end{array}$ & $\begin{array}{l}24 \\
23\end{array}$ & $\begin{array}{l}18-60 \\
18-60\end{array}$ & $\begin{array}{l}16.4 \pm 2.6 \\
15.8 \pm 2.7\end{array}$ & 3 (Jadad score) & (20) \\
\hline Cao et al & $\mathrm{RCT}$ & $\begin{array}{l}\text { PCNL } \\
\text { RIRS }\end{array}$ & $\begin{array}{l}123 \\
120\end{array}$ & $\begin{array}{l}20-72 \\
21-71\end{array}$ & $\begin{array}{l}23 \pm 9 \\
24 \pm 9\end{array}$ & 3 (Jadad score) & (21) \\
\hline Yang et al & Cohort & $\begin{array}{l}\text { PCNL } \\
\text { RIRS }\end{array}$ & $\begin{array}{l}52 \\
68\end{array}$ & $\begin{array}{l}20-50 \\
20-50\end{array}$ & $\begin{array}{l}<20 \\
<20\end{array}$ & 7 & (22) \\
\hline Zhu et al & Cohort & $\begin{array}{l}\text { PCNL } \\
\text { RIRS }\end{array}$ & $\begin{array}{l}24 \\
23\end{array}$ & $\begin{array}{l}44.13 \pm 7.11 \\
44.13 \pm 7.11\end{array}$ & $\begin{array}{l}\text { NR } \\
\text { NR }\end{array}$ & 6 & (23) \\
\hline Yao et al & Cohort & $\begin{array}{l}\text { PCNL } \\
\text { RIRS }\end{array}$ & $\begin{array}{l}45 \\
64\end{array}$ & $\begin{array}{l}21-73 \\
21-73\end{array}$ & $\begin{array}{l}24 \pm 7 \\
25 \pm 9\end{array}$ & 7 & (24) \\
\hline $\mathrm{He}$ & $\mathrm{RCT}$ & $\begin{array}{l}\text { PCNL } \\
\text { RIRS }\end{array}$ & $\begin{array}{l}20 \\
18\end{array}$ & $\begin{array}{l}43.5 \pm 2.3 \\
43.5 \pm 2.3\end{array}$ & $\begin{array}{l}\text { NR } \\
\text { NR }\end{array}$ & 3 (Jadad score) & $(25)$ \\
\hline Yang et al & Cohort & $\begin{array}{l}\text { PCNL } \\
\text { RIRS }\end{array}$ & $\begin{array}{l}50 \\
67\end{array}$ & $\begin{array}{l}21-73 \\
21-73\end{array}$ & $\begin{array}{l}24 \pm 7 \\
25 \pm 9\end{array}$ & 7 & (26) \\
\hline Kruck et al & Cohort & $\begin{array}{l}\text { PCNL } \\
\text { RIRS }\end{array}$ & $\begin{array}{l}108 \\
172\end{array}$ & $\begin{array}{c}53.3 \pm 14.8 \\
50 \pm 16.7\end{array}$ & $\begin{array}{c}12.6 \pm 9.5 \\
6.8 \pm 6.9\end{array}$ & 7 & $(27)$ \\
\hline Resorlu et al & Cohort & $\begin{array}{l}\text { PCNL } \\
\text { RIRS }\end{array}$ & $\begin{array}{r}140 \\
46\end{array}$ & $\begin{array}{l}36.4 \pm 19.7 \\
29.6 \pm 20.3\end{array}$ & $\begin{array}{l}17.3 \pm 3.6 \\
15.6 \pm 3.4\end{array}$ & 7 & $(28)$ \\
\hline Chung et al & Cohort & $\begin{array}{l}\text { PCNL } \\
\text { RIRS }\end{array}$ & $\begin{array}{l}15 \\
12\end{array}$ & $\begin{array}{c}58 \\
58.5\end{array}$ & $\begin{array}{l}10-20 \\
10-19\end{array}$ & 7 & (29) \\
\hline Wiesenthal et al & Cohort & $\begin{array}{l}\text { PCNL } \\
\text { RIRS }\end{array}$ & $\begin{array}{l}43 \\
41\end{array}$ & $\begin{array}{l}52.5 \pm 15.1 \\
53.3 \pm 14.2\end{array}$ & $\begin{array}{l}10-20 \\
10-20\end{array}$ & 7 & (30) \\
\hline Bozkurt et al & Cohort & $\begin{array}{l}\text { PCNL } \\
\text { RIRS }\end{array}$ & $\begin{array}{l}42 \\
37\end{array}$ & $\begin{array}{l}47.4 \pm 15.5 \\
41.2 \pm 13.6\end{array}$ & $\begin{array}{l}15-20 \\
15-20\end{array}$ & 7 & (31) \\
\hline
\end{tabular}

Data are presented as $\mathrm{N}$ or the mean \pm standard deviation. NOS, Newcastle-Ottawa scale; PCNL, percutaneous nephrolithotripsy; RIRS, retrograde intrarenal surgery; $\mathrm{SD}$, standard deviation; $\mathrm{RCT}$, randomized controlled trial; NR, not reported.

the included studies (heterogeneity: $\mathrm{P}=0.001, \mathrm{I}^{2}=58.6 \%$ ). Subsequently, we performed subgroup analysis according to stone size and study design to explore the potential sources of heterogeneity.

Pooled estimates suggested that RIRS had a significant lower stone-free rate than PCNL in the treatment of renal stones $<2 \mathrm{~cm}(\mathrm{RR}=0.96,95 \% \mathrm{CI}$ : 0.93 to $1.00 ; \mathrm{P}=0.031)$ and $\geq 2 \mathrm{~cm}$ ( $\mathrm{RR}=0.74,95 \% \mathrm{CI}: 0.68$ to 0.82 ; $\mathrm{P}<0.001$; Fig. 3 ). Subgroup analysis based on RCTs showed that the stone-free rate was similar between the two groups $(R R=0.88,95 \% \mathrm{CI}$ : 0.76 to $1.01 ; \mathrm{P}=0.078$, whereas pooled results from cohort studies revealed a significant higher stone-free rate in the PCNL group than that in the RIRS group $(\mathrm{R} R=0.90,95 \% \mathrm{CI}$ : 0.85 to $0.96 ; \mathrm{P}=0.002$; Fig. 2).

Hospital stay. In total, 12 studies presented hospital stay data (15-17,20,22,24-28,30,31). Aggregated results using a random effects model suggested that patients treated with RIRS had a significantly shorter hospital stay than those treated with PCNL (WMD=-2.72, 95\% CI: -3.9 to -1.54 ; P<0.001; Fig. 4). The test for heterogeneity among the individual studies was significant (heterogeneity: $\mathrm{P}<0.001, \mathrm{I}^{2}=98.4 \%$ ). Therefore, we 


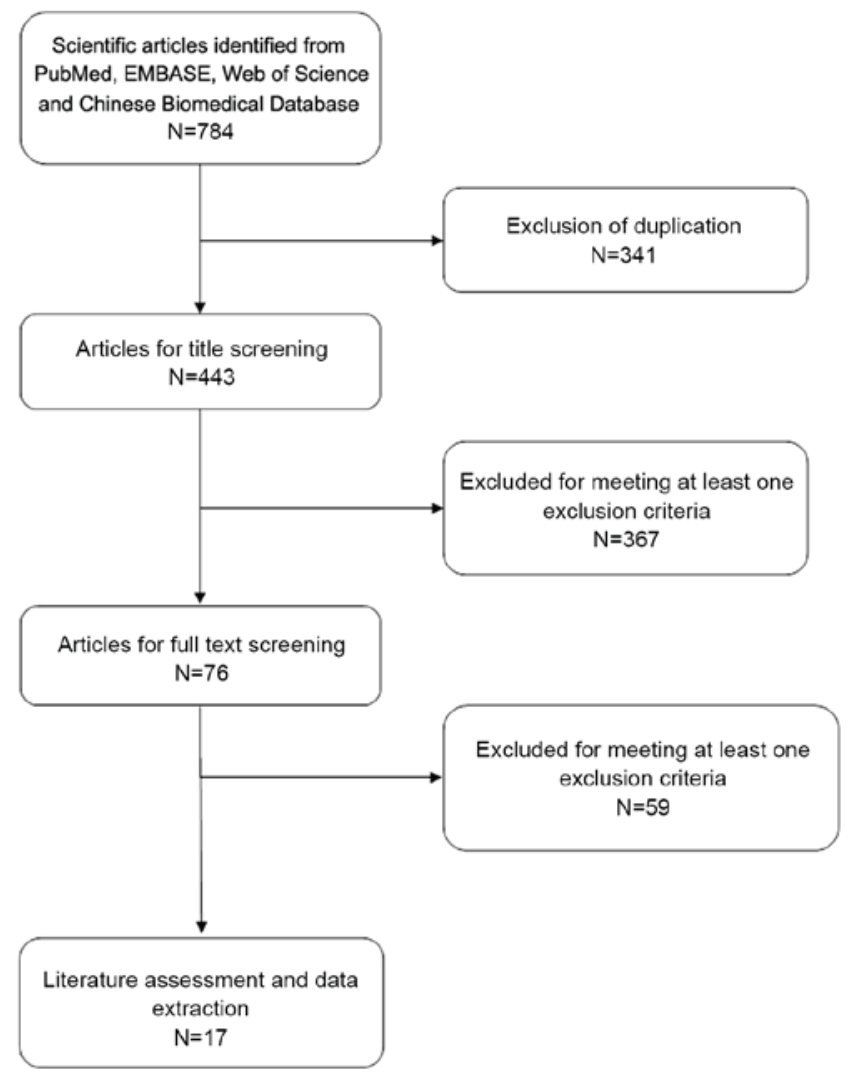

Figure 1. Eligibility of studies for inclusion in the present meta-analysis.

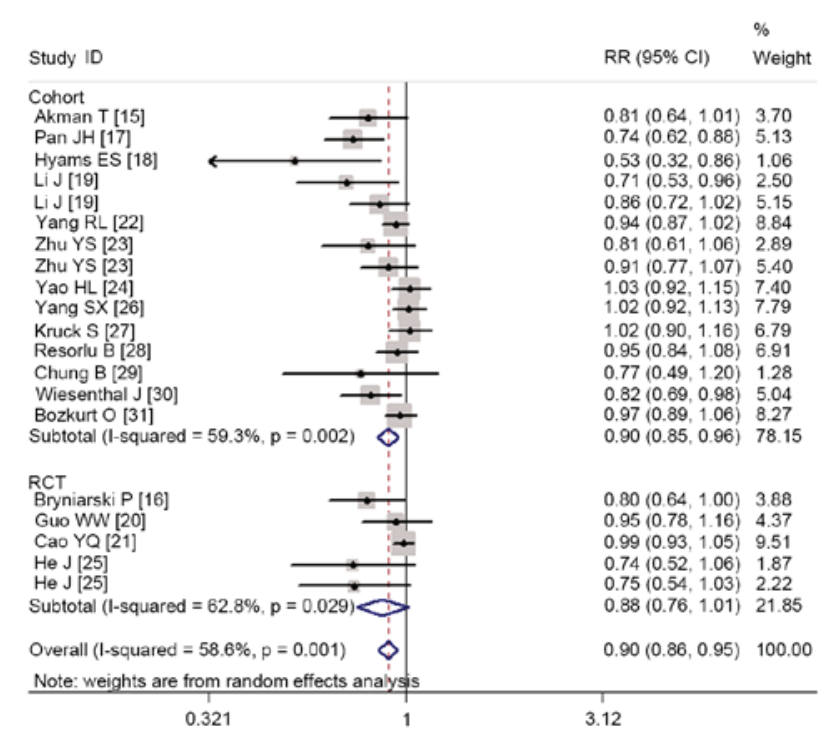

Figure 2. Comparison of percutaneous nephrolithotripsy or retrograde intrarenal surgery for patients with renal stones in terms of stone-free rate. RR, relative risk; $\mathrm{CI}$, confidence interval.

performed subgroup analysis based on stone size and study design to explore the potential sources of heterogeneity.

Subgroup analysis based on stone size revealed that RIRS was associated with a significantly shorter hospital stay in patients with stone sizes $<2 \mathrm{~cm}$ (WMD $=-2.18,95 \% \mathrm{CI}:-3.54$ to $-0.82 ; \mathrm{P}=0.002)$ and $\geq 2 \mathrm{~cm}(\mathrm{WMD}=-4.15,95 \% \mathrm{CI}:-6.00$ to $-2.30 ; \mathrm{P}<0.001$; Fig. 4). Subgroup analysis based on study design demonstrated that both RCTs and cohort studies

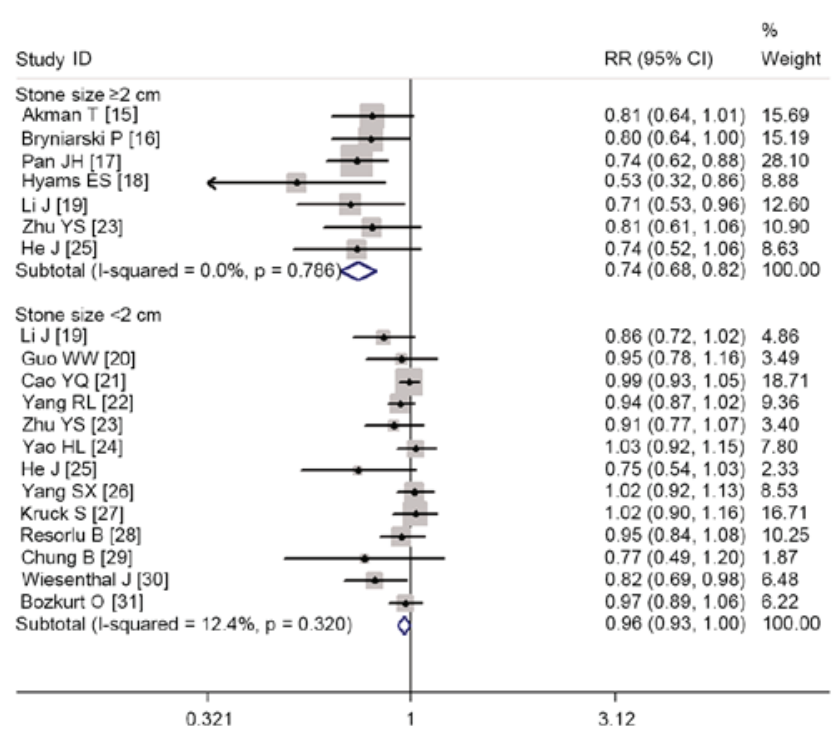

Figure 3. Comparison of percutaneous nephrolithotripsy or retrograde intrarenal surgery on stone-free rate in the subgroup analysis according to stone size. RR, relative risk; CI, confidence interval.

demonstrated a significantly shorter hospital stay in the RIRS group than that in the PCNL group (RCTs: WMD=-4.3, 95\% CI: -4.94 to -3.66 ; $\mathrm{P}<0.001$; cohort studies: $\mathrm{WMD}=-1.96$, 95\% CI: -3.27 to -0.64 ; $\mathrm{P}=0.004$; Fig. 5).

Operation time. A total of 14 studies provided operation time data $(15-17,19-26,28,29,31)$. Pooled results showed that there was no significant difference in operation time between the two groups (WMD=7.86, 95\% CI: -0.89 to 16.61 ; $\mathrm{P}=0.078$; Fig. 6). The test for heterogeneity was significant (heterogeneity: $\mathrm{P}<0.001, \mathrm{I}^{2}=97.9 \%$ ). Consequently, we performed subgroup analysis based on stone size and study design to explore the potential sources of heterogeneity.

Subgroup-analysis based on stone size indicated that RIRS was associated with a significantly longer operation time in patients with stone sizes $\geq 2 \mathrm{~cm}$ (WMD $=12.88,95 \% \mathrm{CI}: 4.77$ to $20.99 ; \mathrm{P}=0.002$ ), but a similar operation time in patients with stone sizes $<2 \mathrm{~cm}$ was found between RIRS and PCNL (WMD=5.49, 95\% CI: -6.92 to $17.90 ; \mathrm{P}=0.386$; Fig. 6). Subgroup analysis based on study design revealed that both RCTs and cohort studies exhibited a similar operation time between the RIRS and PCNL groups (RCTs: WMD=8.85, 95\% CI: -5.34 to $23.04 ; \mathrm{P}=0.222$; cohort studies: $\mathrm{WMD}=7.5$, 95\% CI: -3.10 to $18.11 ; \mathrm{P}=0.165$; Fig. 7 ).

Complication rate. In total, 11 studies reported complication rate data (17,19-21,24,26-31). Pooled results using a fixed-effect model showed that there was no significant difference in complication rates between the RIRS and PCNL groups ( $R R=0.71,95 \%$ CI: 0.48 to $1.05 ; \mathrm{P}=0.083$ ). The test for heterogeneity did not indicate a significant difference (heterogeneity: $\mathrm{P}=0.900, \mathrm{I}^{2}=0.0 \%$; Fig. 8).

Publication bias. Begg's and Egger's test were used to evaluate publication bias, and these results revealed that no potential publication bias existed among the included studies (Egger's test, $\mathrm{P}=0.120$; Begg's test, $\mathrm{P}=0.243$ ). 


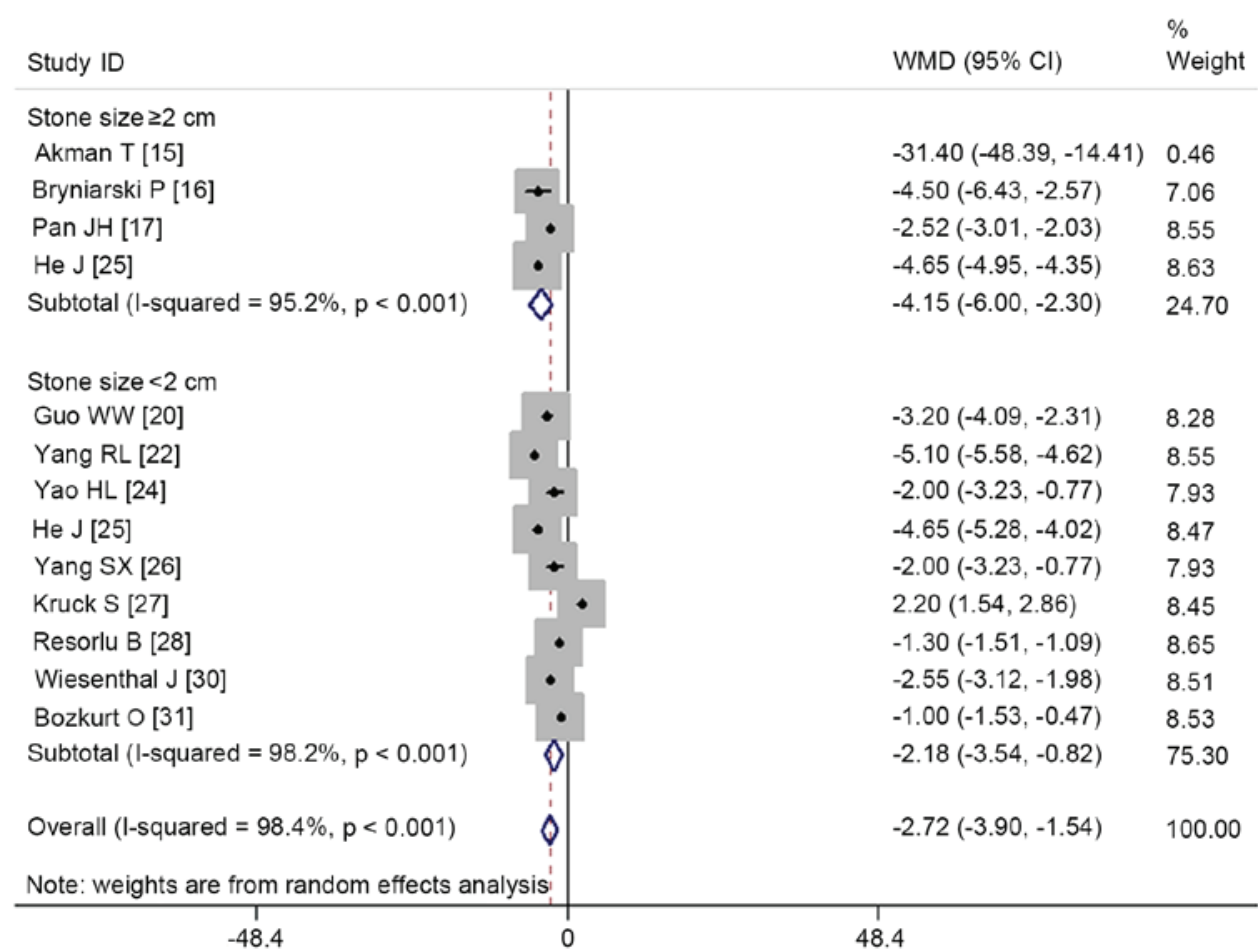

Figure 4. Comparison of percutaneous nephrolithotripsy or retrograde intrarenal surgery for patients with renal stones in terms of hospital stay. WMD, weighted mean difference; $\mathrm{CI}$, confidence interval.

\begin{tabular}{|c|c|c|c|}
\hline Study ID & & WMD $(95 \% \mathrm{Cl})$ & $\begin{array}{l}\% \\
\text { weight }\end{array}$ \\
\hline \multicolumn{4}{|l|}{ Cohort } \\
\hline Akman T [15] & 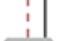 & $-31.40(-48.39,14.41)$ & 0.46 \\
\hline Pan JH [17] & - & $-2.52(-3.01,-2.03)$ & 8.55 \\
\hline Yang RL [22] & - I & $-5.10(-5.58,-4.62)$ & 8.55 \\
\hline Yao HL [24] & + & $-2.00(-3.23,-0.77)$ & 7.93 \\
\hline Yang SX [26] & + & $-2.00(-3.23,-0.77)$ & 7.93 \\
\hline Kruck S [27] & i & $2.20(1.54,2.86)$ & 8.45 \\
\hline Resorlu B [28] & • & $-1.30(-1.51,-1.09)$ & 8.65 \\
\hline Wiesenthal J [30] & - & $-2.55(-3.12,-1.98)$ & 8.51 \\
\hline Bozkurt O [31] & - & $-1.00(-1.53,-0.47)$ & 8.53 \\
\hline Subtotal $(\mathrm{I}$-squared $=97.9 \%, p<0.001)$ & 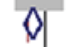 & $-1.96(3.27,-0.64)$ & 67.57 \\
\hline \multicolumn{4}{|l|}{$\mathrm{RCT}$} \\
\hline Bryniarski P [16] & $\leftarrow$ & $-4.50(-6.43,-2.57)$ & 7.06 \\
\hline Guo WW [20] & $\bullet$ & $-3.20(-4.09,-2.31)$ & 8.28 \\
\hline $\mathrm{He} \mathrm{J} \mathrm{[25]}$ & - & $-4.65(-4.95,-4.35)$ & 8.63 \\
\hline $\mathrm{He} \mathrm{J}[25]$ & - & $-4.65(-5.28,-4.02)$ & 8.47 \\
\hline Subtotal $(\mathrm{I}$-squared $=68.2 \%, \mathrm{p}=0.024)$ & 8 & $-4.30(-4.94,-3.66)$ & 32.43 \\
\hline Overall (I-squared $=98.4 \%, p<0.001)$ & $\Delta$ & $-2.72(-3.90,-1.54)$ & 100.00 \\
\hline \multicolumn{4}{|l|}{ Note: weights are from random effects analysis } \\
\hline $\begin{array}{ll} & 1 \\
-48.4\end{array}$ & 0 & 3.4 & \\
\hline
\end{tabular}

Figure 5. Comparison of percutaneous nephrolithotripsy or retrograde intrarenal surgery on hospital stay in the subgroup analysis according to study design. WMD, weighted mean difference; $\mathrm{CI}$, confidence interval.

\section{Discussion}

This meta-analysis was performed with the objective of comparing clinical outcomes between RIRS and PCNL for the management of renal stones. Based on 17 studies, the results from our meta-analysis suggested that PCNL was associated with a higher stone-free rate, but a longer hospital stay, when compared with RIRS. There was no significant difference between the two groups in terms of operation time and complication rate. However, subgroup analysis based on stone size 


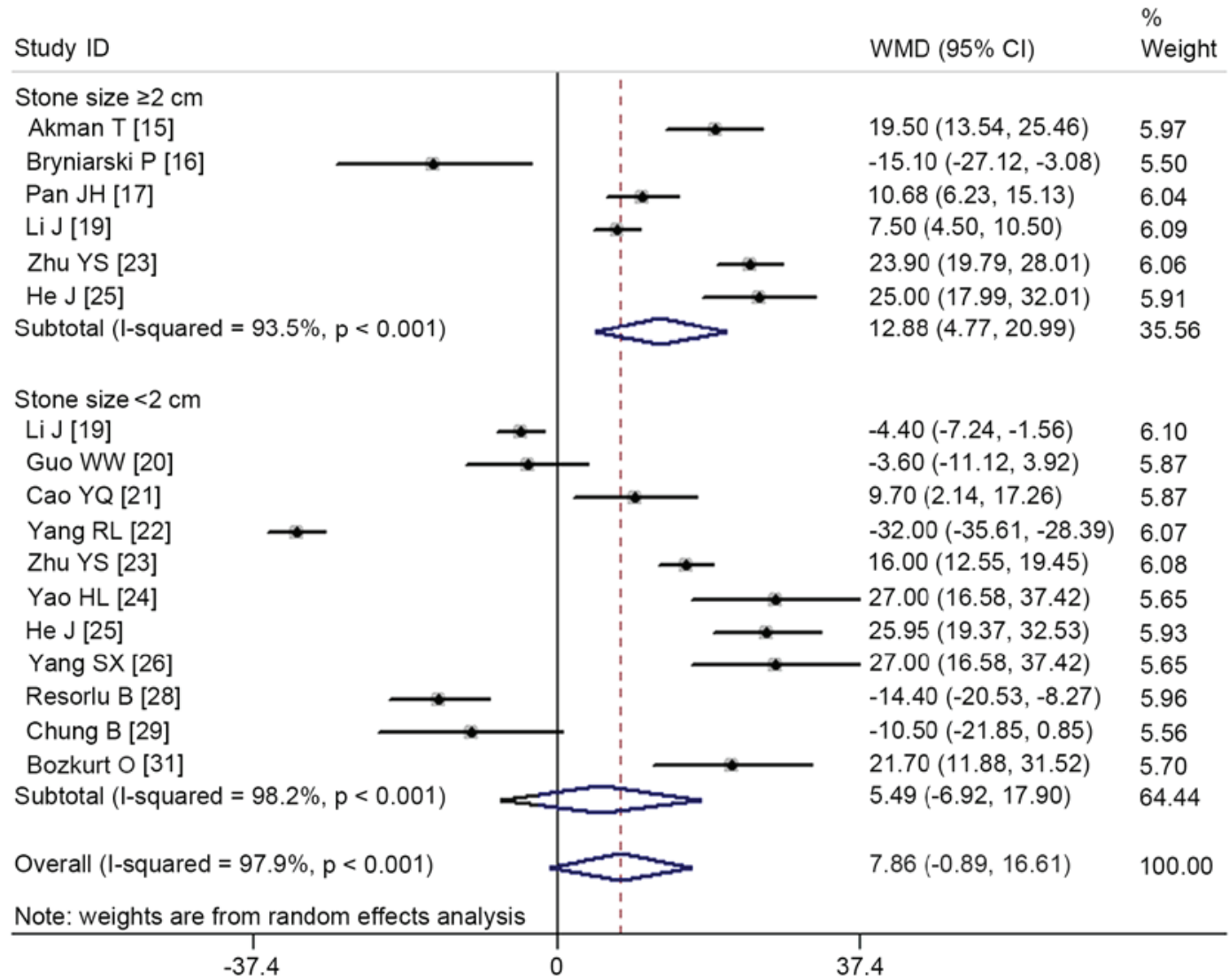

Figure 6. Comparison of percutaneous nephrolithotripsy or retrograde intrarenal surgery for patients with renal stones in terms of operation time. WMD, weighted mean difference; CI, confidence interval.

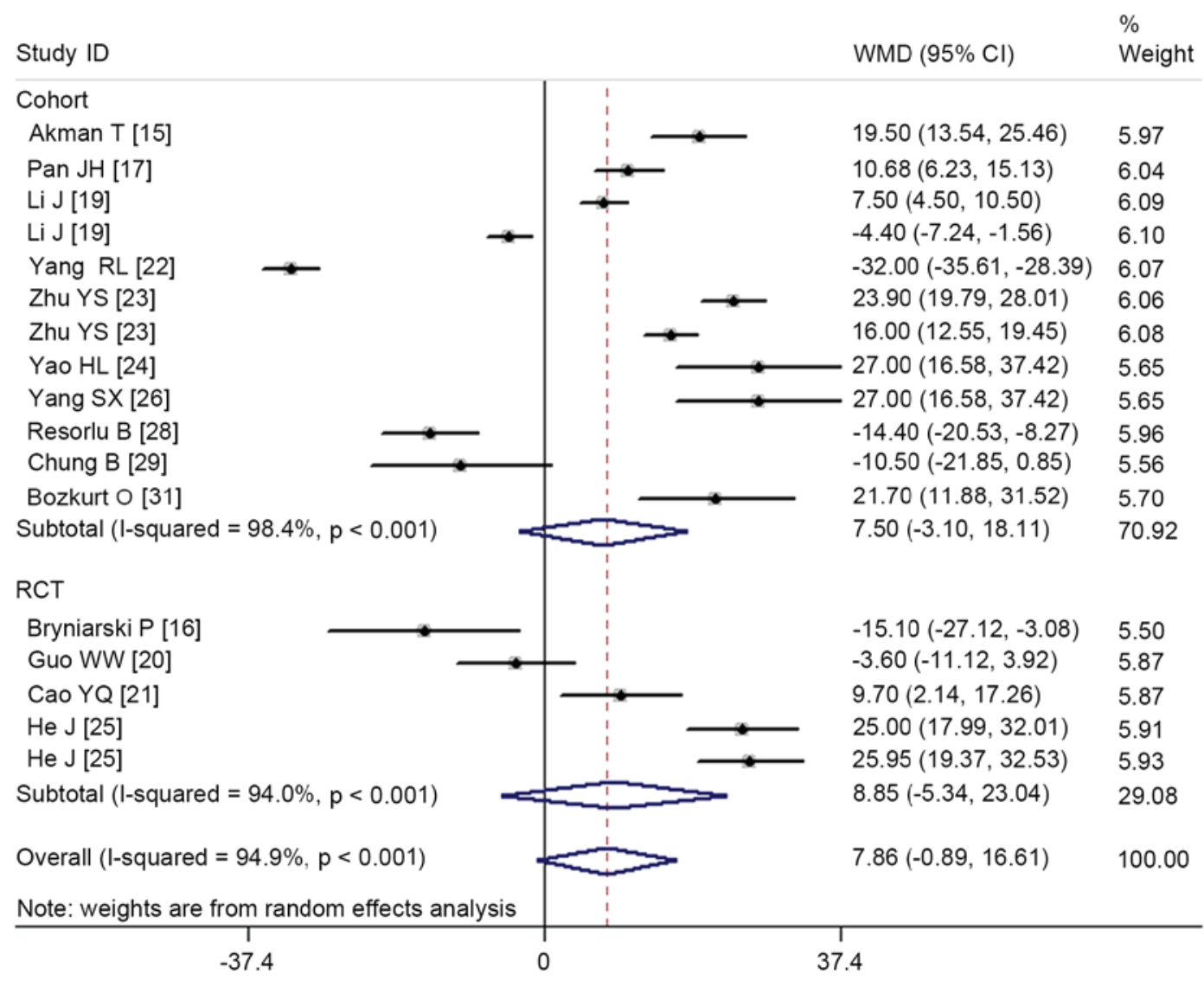

Figure 7. Comparison of percutaneous nephrolithotripsy or retrograde intrarenal surgery on operation time in the subgroup analysis according to study design. WMD, weighted mean difference; CI, confidence interval. 


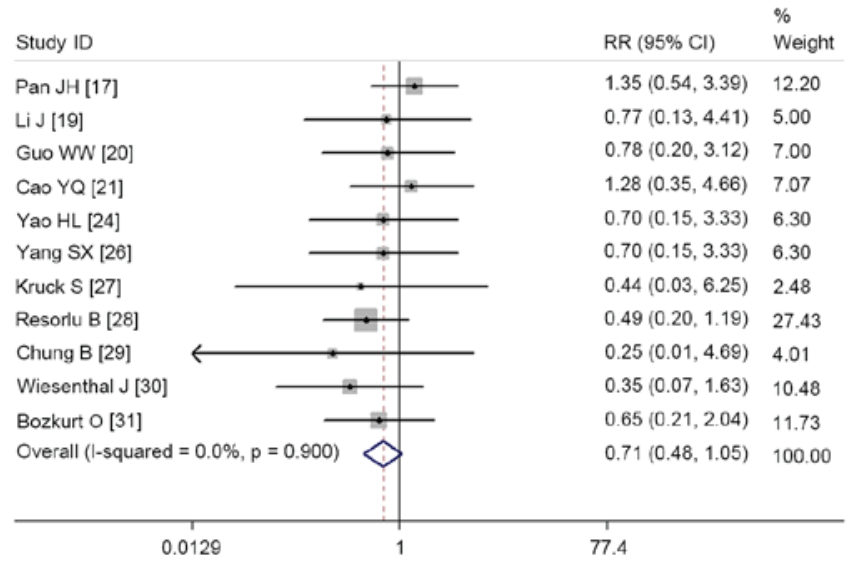

Figure 8. Comparison of percutaneous nephrolithotripsy or retrograde intrarenal surgery for patients with renal stones in terms of complication rate. RR, relative risk; $\mathrm{CI}$, confidence interval.

showed that PCNL had a shorter operation time than RIRS in patients with stone sizes measuring $\geq 2 \mathrm{~cm}$. Subgroup analysis conducted on RCTs demonstrated that the stone-free rate between the two groups was not significant.

PCNL is recommended as the first-line treatment for kidney stones measuring $>2 \mathrm{~cm}$ and also for complex renal stones (32). Although this procedure has the advantage of high stone clearance rates, it is an invasive method that may result in serious complications. However, with the technical improvements in flexible ureteroscope, RIRS with holmium laser lithotripsy has become an effective and safe choice for larger renal stones $(6,33)$. Furthermore, since it is less invasive than conventional PCNL, URS/laser lithotripsy has been chosen by an increasing number of patients for the treatment of renal stones, particularly for stones in an intermediate size range of $2-3 \mathrm{~cm}$ (34). Even so, this technique has several disadvantages, including the high retreatment rate, high cost of flexible ureteroscopic replacement and repair (34).

The present meta-analysis demonstrated that the stone-free rate of RIRS was lower than that of PCNL, but additional sessions of RIRS achieved comparable stone-free rates with PCNL. According to previous studies, the overall success rate of RIRS ranged from 77 to $93 \%$ after additional sessions for intrarenal calculi larger than $2 \mathrm{~cm}(6,35-39)$. Breda et al (6) assessed the efficacy and safety of ureteroscopic lithotripsy for single intrarenal stones of sizes $20-25 \mathrm{~mm}$. They found that the mean post-procedural success rate was $93 \%$ after an average of 2.3 sessions (6). Riley et al (37) reported that for an average stone size of $3.0 \mathrm{~cm}$, the success rate of RIRS treatment was $90.9 \%$. In patients with stones measuring $>3 \mathrm{~cm}, 91.6 \%$ were stone-free after an average of 1.9 procedures; patients with stones $>3.5 \mathrm{~cm}, 80 \%$ were stone-free after an average of 1.8 procedures; and patients with stones larger than $4 \mathrm{~cm}, 50 \%$ were stone-free after an average of 2 procedures (37).

According to this meta-analysis, PCNL had significant higher stone-free rate than RIRS. However, when the data was pooled from RCTs, this significant difference was not observed. Guo et al (20) conducted a RCT to compare PCNL and flexible ureteroscope holmium laser lithotripsy for $1-2 \mathrm{~cm}$ renal calculi. They reported that the stone-free rates for the two groups were 91.7 and $86.9 \%$, respectively, with no significant difference. Similar results were observed in the RCT conducted by Cao et al (21), in which PCNL and RIRS were used to treat patients with renal calculi $<3 \mathrm{~cm}$ in diameter; the stone-free rates for these two groups were 95.1 and $94.2 \%$, respectively (21). There was no significant difference between these values. However, in a RCT conducted by Bryniarski et al (16), the stone-free rate in the PCNL group (94\%) was significant higher than that in the RIRS group (75\%). Since the stone size in these RCTS was variable, further well-performed, high-homogeneity RCTs are required to evaluate whether PCNL has higher stone-free rate than RIRS.

The main reason for the lower disintegration rate in RIRS compared with PCNL is that larger fragments fall back into the lower calix where they cannot be accessed with a semirigid ureteroscope. A flexible ureteroscope was then used by the urologists to disintegrate them; however, most urologists failed to leave the kidneys without any stone debris. Notably, Smith et al (40) described a technique to avoid such failure. At the beginning of procedure, they filled the lower calix with autologous blood, meaning that the stone debris would not fall back there during disintegration (40). Since few studies using this technique to manage patients with renal stone have been published, further studies are warranted to identify whether this technique would increase the disintegration rate.

In this meta-analysis, we found that there was no significant difference in operation time between the two groups. The mean operation times for PCNL and RIRS group were $61.49 \pm 14.17$ and $69.37 \pm 16.89 \mathrm{~min}$, respectively. Previous studies have reported that prolonged operation time was associated with several complications. Akman et al (41) found that operative time longer than 58 min would increase 2.82 times risk of needing for blood transfusion when patients were managed with PCNL. Moreover, Kukreja et al (42) reported that diabetes mellitus, a multiple access tract procedure and prolonged operative time, were associated with blood loss during the PCNL procedure (42). However, whether prolonged operative time in RIRS would increase the risk of bleeding remains unknown.

This meta-analysis found that RIRS had a shorter hospital stay than the PCNL. This result was observed in all of the included studies. In most western countries, RIRS is considered as an outpatient procedure in which patients are discharged after $24 \mathrm{~h}$; whereas, PCNL usually requires 2 days of hospitalization. Of the included studies, Bryniarski et al (16) reported the longest hospital stay, in which the hospital stays for the PCNL and RIRS group were $11.3 \pm 4.4$ and $6.8 \pm 3.4$ days, respectively. The authors explained the prolonged hospitalization. Firstly, the approach they used from the procedural causes was different, thus patients required a longer hospital stay; secondly, they used a wide ureteroscope for RIRS (16). In order to avoid potential strictures, patients were required to remain in hospital for longer to ensure the ureters were able to recover with ureteral stents inserted (16).

With regards to the complications, no significant difference between the PCNL and RIRS group was found in this meta-analysis. Despite this, several complications related with PCNL or RIRS should not be ignored. Percutaneous access is the main reason for the complications. Severe complications would result in damage to the renal parenchyma and adjacent 
structures. The PCNL procedure is associated with several complications, including bleeding requiring blood transfusion, septicaemia, colonic injury, fever and urinary infection $(43,44)$. Bleeding requiring transfusion is one of the most important complications, the incidence of which has been reported to range from 0.8 to $45 \%$ in the PCNL literature (43-45). Urosepsi is one of the most important complications related with RIRS. Takazawa et al (46) reported that $15 \%$ of the patients with renal stones measuring $\geq 2 \mathrm{~cm}$ presented a high-grade fever with urosepsis when they were treated with flexible ureteroscopic lithotripsy (46). This severe complication could be explained by two main reasons: Intrarenal reflux-containing bacteria from infectious stones during fragmentation, and a long operative time (46).

There are several potential limitations to this meta-analysis that should be considered. Firstly, of the 17 studies, only 4 were RCTs, and the remaining 13 were cohort studies. Despite the reasoning that cohort studies may reflect the real-world and further support the conclusion, cohort data are associated with bias due to patient selection. Secondly, 10 of the studies included had a relatively small sample size $(\mathrm{n}<100)$. Although all of these studies were well-performed, high-quality trials, our conclusions should be interpreted with caution because studies with small sample size are more likely to overestimate the treatment effect than those with larger sample sizes. Thirdly, the characteristics (age, sex, stone number, stone localization and stone size), and study designs varied considerably among the included studies. These factors may increase the heterogeneity and affect the pooled estimates. Therefore, physicians should interpret our findings with caution when applying them to clinical practice.

In conclusion, the findings of the present meta-analysis indicated that PCNL had a higher stone-free rate, but longer hospital stay, in comparison with RIRS. Operation time and complication rate between the two groups were comparable. Therefore, we propose that RIRS may be an alternative therapy to PCNL, with acceptable efficacy and complication rates for renal stones. However, considering the potential limitations of this study, further large-scale, well-conducted RCTs are required to verify our findings.

\section{Acknowledgements}

The present study was supported by the Medical Scientific Research Foundation of Zhejiang Province, China (grant nos. 2015DTA017 and 2016ZHA005).

\section{References}

1. Stamatelou KK, Francis ME, Jones CA, Nyberg LM and Curhan GC: Time trends in reported prevalence of kidney stones in the United States: 1976-1994. Kidney Int 63: 1817-1823, 2003.

2. Preminger GM, Assimos DG, Lingeman JE, Nakada SY, Pearle MS and Wolf JS Jr; AUA Nephrolithiasis Guideline Panel: Chapter 1: AUA guideline on management of staghorn calculi: Diagnosis and treatment recommendations. J Urol 173: 1991-2000, 2005.

3. Michel MS, Trojan L and Rassweiler JJ: Complications in percutaneous nephrolithotomy. Eur Urol 51: 899-906, 2007.

4. de la Rosette J, Assimos D, Desai M, Gutierrez J, Lingeman J, Scarpa R and Tefekli A; CROES PCNL Study Group: The clinical research office of the endourological society percutaneous nephrolithotomy global study: Indications, complications, and outcomes in 5,803 patients. J Endourol 25: 11-17, 2011.
5. Traxer O, Dubosq F, Jamali K, Gattegno B and Thibault P: New-generation flexible ureterorenoscopes are more durable than previous ones. Urology 68: 276-281, 2006.

6. Breda A, Ogunyemi O, Leppert JT, Lam JS and Schulam PG: Flexible ureteroscopy and laser lithotripsy for single intrarenal stones $2 \mathrm{~cm}$ or greater-is this the new frontier? J Urol 179: 981-984, 2008.

7. Jadad AR, Moore RA, Carroll D, Jenkinson C, Reynolds DJ, Gavaghan DJ and McQuay HJ: Assessing the quality of reports of randomized clinical trials: Is blinding necessary? Control Clin Trials 17: 1-12, 1996.

8. Kjaergard LL, Villumsen J and Gluud C: Reported methodologic quality and discrepancies between large and small randomized trials in meta-analyses. Ann Intern Med 135: 982-989, 2001.

9. Wells G, Shea B, O'connell D, Peterson J and Welch V: The Newcastle-Ottawa Scale (NOS) for assessing the quality of nonrandomized studies in meta-analyses. 3rd Symposium on Systematic Reviews: Beyond the Basics: 3-5, 2000.

10. DerSimonian R and Laird N: Meta-analysis in clinical trials. Control Clin Trials 7: 177-188, 1986.

11. Higgins JP, Thompson SG, Deeks JJ and Altman DG: Measuring inconsistency in meta-analyses. BMJ 327: 557-560, 2003.

12. Mantel $\mathrm{N}$ and Haenszel W: Statistical aspects of the analysis of data from retrospective studies of disease. J Natl Cancer Inst 22: 719-748, 1959.

13. Begg CB and Mazumdar M: Operating characteristics of a rank correlation test for publication bias. Biometrics 50: 1088-1101, 1994.

14. Egger M, Davey Smith G, Schneider M and Minder C: Bias in meta-analysis detected by a simple, graphical test. BMJ 315: 629-634, 1997.

15. Akman T, Binbay M, Ozgor F, Ugurlu M, Tekinarslan E, Kezer C, Aslan R and Muslumanoglu AY: Comparison of percutaneous nephrolithotomy and retrograde flexible nephrolithotripsy for the management of 2-4 cm stones: A matched-pair analysis. BJU Int 109: 1384-1389, 2012.

16. Bryniarski P, Paradysz A, Zyczkowski M, Kupilas A, Nowakowski K and Bogacki R: A randomized controlled study to analyze the safety and efficacy of percutaneous nephrolithotripsy and retrograde intrarenal surgery in the management of renal stones more than $2 \mathrm{~cm}$ in diameter. J Endourol 26: 52-57, 2012.

17. Pan J, Chen Q, Xue W, Chen Y, Xia L, Chen H and Huang Y: RIRS versus mPCNL for single renal stone of $2-3 \mathrm{~cm}$ : Clinical outcome and cost-effective analysis in Chinese medical setting. Urolithiasis 41: 73-78, 2013.

18. Hyams ES and Shah O: Percutaneous nephrostolithotomy versus flexible ureteroscopy/holmium laser lithotripsy: Cost and outcome analysis. J Urol 182: 1012-1017, 2009.

19. Li J, Wang J, Li Y, Tong F, Zhai C and Ye L: Comparative study of transurethral flexible ureteroscope lithotripsy and minimally invasive percutaneous nephrolithotomy in treatment of renal calyceal calculi. J Kunming Med Univ 36: 134-136, 2015.

20. Guo W, Yan R, Wang L, Zhang J and Liu C: Percutaneous nephrolithotomy versus flexible ureteroscope holmium laser lithotripsy for renal calculi. Int Med Health Guidance News 21: 1520-1524, 2015 (In Chinese).

21. Cao Y, Jiang Z and Shi L: Comparison of the clinical efficacy of percutaneous nephrolithotomy and ureteroscopy for the treatment of renal calculi. Int J Urol Nephrol 34: 805-808, 2014.

22. Yang R, Kang $\mathbf{J}$ and Chen D: Flexible ureteroscopy and percutaneous nephrolithotomy holmium laser lithotripsy for renal calculi $(<2 \mathrm{~cm})$ clinical effect comparison. Med Infor 28: 37-38, 2015.

23. Zhu Y, Su H and Deng Q: Comparative efficacy analysis of flexible ureteroscopic lithotripsy and percutaneous nephrolithotomy for treatment of renal calyceal stones. J Luzhou Med Col: 382-383, 2013.

24. Yao H, Song C and Liu L: Comparison of therapeutic effects of renal calculi witll ureteroscopic holminum laser fithotripsy versus percutaneous nephrostofithotripsy. J Clin Surg 21: 802-803, 2013

25. He J: Comparison of the clinical efficacy of percutaneous nephrolithotomy and ureteroscopy for the treatment of renal calculi. Med Aesthetics Cosmetol: 697, 2015.

26. Yang S, Song C, Liu L, et al: Management of renal calculi: Retrograde ureteroscopic holminum laser versus percutaneous nephrolithotripsy. Chin J Urol 34: 666-669, 2013.

27. Kruck S, Anastasiadis AG, Herrmann TR, Walcher U, Abdelhafez MF, Nicklas AP, Hölzle L, Schilling D, Bedke J, Stenzl A and Nagele U: Minimally invasive percutaneous nephrolithotomy: An alternative to retrograde intrarenal surgery and shockwave lithotripsy. World J Urol 31: 1555-1561, 2013. 
28. Resorlu B, Unsal A, Ziypak T, Diri A, Atis G, Guven S, Sancaktutar AA, Tepeler A, Bozkurt OF and Oztuna D Comparison of retrograde intrarenal surgery, shockwave lithotripsy and percutaneous nephrolithotomy for treatment of medium-sized radiolucent renal stones. World J Urol 31: $1581-1586,2013$.

29. Chung BI, Aron M, Hegarty NJ and Desai MM: Ureteroscopic versus percutaneous treatment for medium-size $(1-2-\mathrm{cm})$ renal calculi. J Endourol 22: 343-346, 2008

30. Wiesenthal JD, Ghiculete D, D'A Honey RJ and Pace KT: A comparison of treatment modalities for renal calculi between 100 and $300 \mathrm{~mm} 2$ : Are shockwave lithotripsy, ureteroscopy, and percutaneous nephrolithotomy equivalent? J Endourol 25: 481-485, 2011.

31. Bozkurt OF, Resorlu B, Yildiz Y, Can CE and Unsal A: Retrograde intrarenal surgery versus percutaneous nephrolithotomy in the management of lower-pole renal stones with a diameter of 15 to $20 \mathrm{~mm}$. J Endourol 25: 1131-1135, 2011.

32. Tiselius HG, Alken $P$ and Buck C: Guidelines on urolithiasis. Available at: http://www.uroweb.org/fileadmin/user upload/Guidelines/Urolithiasis.pdf., 2010.

33. Mariani AJ: Combined electrohydraulic and holmium:YAG laser ureteroscopic nephrolithotripsy of large (greater than $4 \mathrm{~cm}$ ) renal calculi. J Urol 177: 168-173, 2007.

34. Hyams ES, Munver R, Bird VG, Uberoi J and Shah O: Flexible ureterorenoscopy and holmium laser lithotripsy for the management of renal stone burdens that measure 2 to $3 \mathrm{~cm}$ : A multi-institutional experience. J Endourol 24: 1583-1588, 2010.

35. El-Anany FG, Hammouda HM, Maghraby HA and Elakkad MA Retrograde ureteropyeloscopic holmium laser lithotripsy for large renal calculi. BJU Int 88: 850-853, 2001.

36. Grasso M, Conlin M and Bagley D: Retrograde ureteropyeloscopic treatment of $2 \mathrm{~cm}$. or greater upper urinary tract and minor Staghorn calculi. J Urol 160: 346-351, 1998.

37. Riley JM, Stearman L and Troxel S: Retrograde ureteroscopy for renal stones larger than $2.5 \mathrm{~cm}$. J Endourol 23: 1395-1398, 2009.

38. Mariani AJ: Combined electrohydraulic and holmium:yag laser ureteroscopic nephrolithotripsy for 20 to $40 \mathrm{~mm}$ renal calculi. J Urol 172: 170-174, 2004.
39. Breda A, Ogunyemi O, Leppert JT and Schulam PG: Flexible ureteroscopy and laser lithotripsy for multiple unilateral intrarenal stones. Eur Urol 55: 1190-1196, 2009.

40. Smith R, Khoubehi B and Fuchs G: Occlusion of the lower calyx by autologuos blood prevents accumulation of stone fragments at this site after retrograde intra-renal surgery. Eur Urol (Suppl 264), 2005.

41. Akman T, Binbay M, Sari E, Yuruk E, Tepeler A, Akcay M, Muslumanoglu AY and Tefekli A: Factors affecting bleeding during percutaneous nephrolithotomy: Single surgeon experience. J Endourol 25: 327-333, 2011.

42. Kukreja R, Desai M, Patel S, Bapat S and Desai M: Factors affecting blood loss during percutaneous nephrolithotomy: Prospective study. J Endourol 18: 715-722, 2004.

43. Segura JW, Patterson DE, LeRoy AJ, Williams HJ Jr, Barrett DM, Benson RC Jr, May GR and Bender CE: Percutaneous removal of kidney stones: Review of 1,000 cases. J Urol 134: 1077-1081, 1985.

44. Stoller ML, Wolf JS Jr and St Lezin MA: Estimated blood loss and transfusion rates associated with percutaneous nephrolithotomy. J Urol 152: 1977-1981, 1994.

45. Liatsikos EN, Kapoor R, Lee B, Jabbour M, Barbalias G and Smith AD: 'Angular percutaneous renal access'. Multiple tracts through a single incision for staghorn calculous treatment in a single session. Eur Urol 48: 832-837, 2005.

46. Takazawa R, Kitayama S and Tsujii T: Successful outcome of flexible ureteroscopy with holmium laser lithotripsy for renal stones $2 \mathrm{~cm}$ or greater. Int J Urol 19: 264-267, 2012.

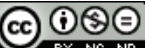

This work is licensed under a Creative Commons Attribution-NonCommercial-NoDerivatives 4.0 International (CC BY-NC-ND 4.0) License. 